\title{
Squamous cell carcinoma of the prostate with concomitant adenocarcinoma in the absence of prior androgen deprivation therapy
}

\author{
Daniel Wesley Abbott ${ }^{1}$, Deepak Kilari ${ }^{2}$, Kathleen Senebouttarath ${ }^{3}$, Kenneth Alan Iczkowski*1 \\ ${ }^{1}$ Department of Pathology, Medical College of Wisconsin, United States \\ ${ }^{2}$ Department of Medicine, Division of Hematology and Oncology, Medical College of Wisconsin, United States \\ ${ }^{3}$ Department of Radiology, Medical College of Wisconsin, United States
}

Received: February 26, 2016

DOI: $10.5430 /$ crcp.v3n2p60
Accepted: April 14, 2016

Online Published: April 25, 2016

\begin{abstract}
We present a case of squamous cell carcinoma of the prostate, unique in that it was accompanied by a spatially separate focus of high-grade adenocarcinoma. Unlike previous case reports, the patient had no history of prior prostatic adenocarcinoma and had no history of treatment with antiandrogen or radiation therapy. Prostate carcinomas with squamous differentiation, while exceedingly rare, carry a poor prognosis compared to adenocarcinomas and should be considered in male patients with obstructive urinary symptoms without increased serum prostate specific antigen.
\end{abstract}

Key Words: Prostate, Squamous carcinoma, Adenosquamous carcinoma, Adenocarcinoma

\section{INTRODUCTION}

Squamous cell carcinoma of the prostate accounts for $<1 \%$ of prostate cancer, affects mostly men over age 70 , and carries a worse prognosis than adenocarcinoma with early metastases to bone, liver, and lungs. ${ }^{[1,2]}$ Median survival is 14 months. ${ }^{[1,3]}$ Here, we present a case with unique findings compared with those in the literature: 1) Squamous cell and adenocarcinoma were diagnosed simultaneously; 2) The patient underwent no prior hormone treatment; 3) The squamous and adenocarcinoma components were spatially separate and on opposite sides of the prostate.

\section{CASE PRESEnTATion}

A 67-year-old African-American man with a past medical history of type II diabetes, atrial fibrillation, hypertension, and benign prostatic hyperplasia was noted to have an increase in his serum prostate specific antigen (PSA), which was previously stable at around $2.0 \mathrm{ng} / \mathrm{ml}$, to $4.8 \mathrm{ng} / \mathrm{ml}$. Digital rectal examination demonstrated an enlarged, firm prostate with a central nodule. TRUS-guided biopsy of the prostate was performed demonstrating a $125 \mathrm{~g}$ gland with keratinizing squamous carcinoma (see Figure 1A) involving most cores on the left side with 20\%-90\% involvement. The squamous cell carcinoma stained negative for S-100 protein, CDX-2, Uroplakin II, and PSA (see Figure 1B). Additionally, Gleason $4+4($ score $=8)$ adenocarcinoma was seen focally (see Figure 2A) in 1 core on the right lateral mid-gland, which showed positive staining for PSA (see Figure 2B). Multifocal prostatic intraepithelial neoplasia was also present on the right side. Staging scans showed no evidence of metas-

\footnotetext{
*Correspondence: Kenneth Alan Iczkowski; Email: kaiczkowski@mcw.edu; Address: Department of Pathology, Medical College of Wisconsin, United States.
} 
tasis. Magnetic resonance imaging of the prostate showed a large lesion measuring $44 \mathrm{~mm} \times 32 \mathrm{~mm}$ involving the left peripheral and central zones with possible posterolateral extracapsular spread (see Figure 3). The mass appeared to invade the periurethral region, and possibly the urethra, displacing the urethra towards the right side. Findings were given a PI-RADS score of 5. Another $6 \mathrm{~mm}$ lesion was seen in the right peripheral zone and scored as PI-RADS 4. Cystoscopy and anoscopy ruled out a primary squamous cell cancer of the bladder/urethra and anal/rectal regions, respectively. Androgen deprivation therapy was started for adenocarcinoma on the right side. Given the lack of randomized prospective data to help guide treatment decisions, it was decided to manage the patient based on extrapolation from squamous cell cancer of the head and neck. Neoadjuvant cisplatin/5-FU was administered for the squamous cell carcinoma, which continued for three cycles. Definitive concurrent chemo-radiation therapy with gemcitabine was started given that he was not a candidate for surgery, secondary to the extent of his disease. Gemcitabine had to be discontinued due to neutropenia after one cycle. His most recent CT scan, obtained 11 months after initial diagnosis, showed stable disease with no evidence of metastasis.

\section{Discussion}

Squamous cell carcinoma most often occurs in the pure form, with around 70 to 80 cases reported. ${ }^{[1,4]}$ The origin is not clear; hypotheses include pure prostatic origin, including the basal cells of the prostatic acini, and squamous metaplasia of a prostatic urethral primary tumor. ${ }^{[1,3,5]}$ Theories of histogenesis include the metaplastic transformation of adenocarcinoma, a collision-type tumor with squamous component developing from metaplastic foci, derivation from pluripotent stem cells capable of multi-directional differentiation, and clonal evolution of treated adenocarcinoma secondary to the selective pressure of therapy. ${ }^{[2,3]}$ Less common is combined squamous cell carcinoma and adenocarcinoma, as in our case, with 26 cases reported in the literature. Cases with a squamous component tended to be associated with higher grade adenocarcinomas, ${ }^{[4]}$ a feature we saw in our case. Most case reports of squamous transformation occurred after radiation or treatment with antiandrogens such as LHRH. ${ }^{[1,6]}$ However, in our case, such a history was not present. Cases of squamous cell carcinoma arising from the prostate associated with schistosomiasis have also been reported. ${ }^{[7]}$

Many of the cases are thought to arise from squamous metaplastic precursors following estrogen treatment or androgen deprivation treatment of adenocarcinoma. ${ }^{[1]}$ Squamous metaplasia tends to be associated with ischemic necrosis and is characterized by fibrous connective tissue devoid of smooth

Published by Sciedu Press muscle cells. ${ }^{[8]}$ Squamous metaplasia occurs during chronic prostatitis, around infarcts, or after estrogen or radiation therapy, but malignant transformation is rare. ${ }^{[3]}$
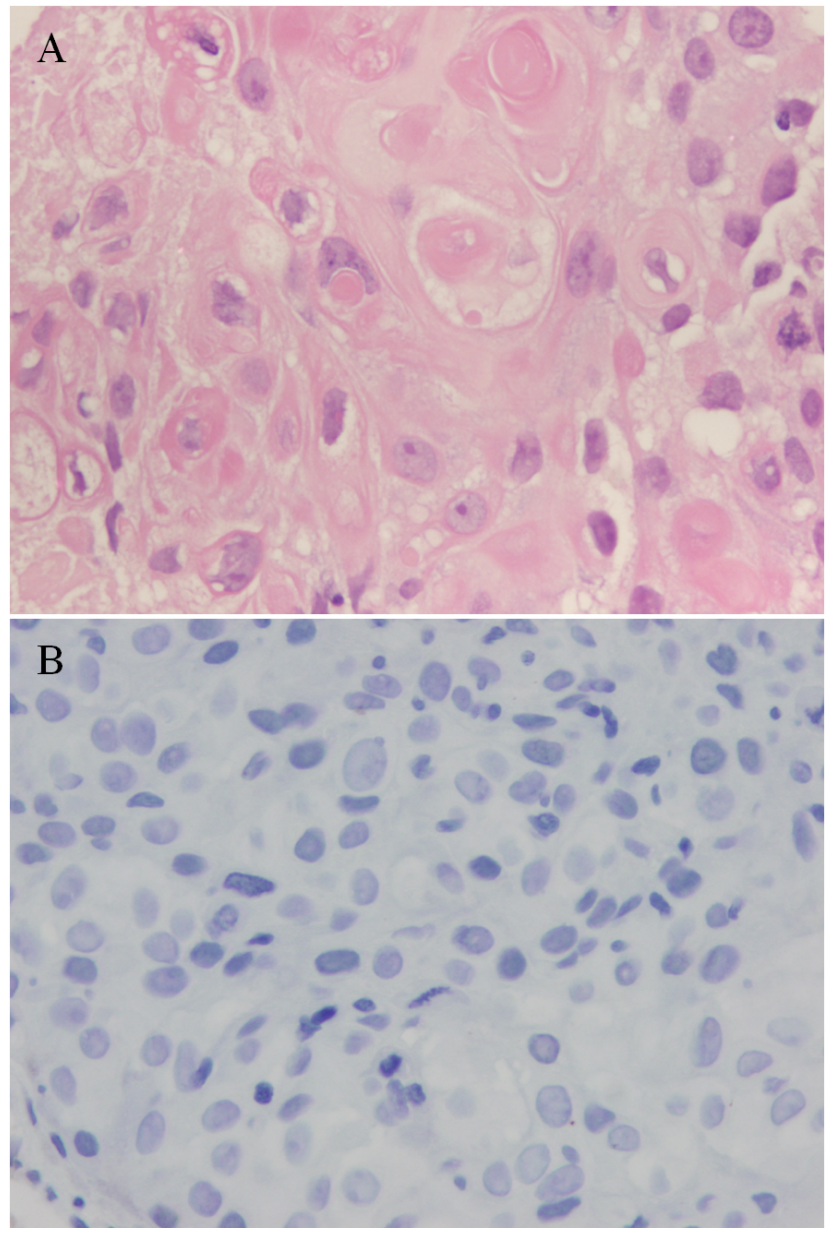

Figure 1. (A) The squamous component contains large cohesive cells characterized by the presence of keratinization and abundant eosinophilic glassy cytoplasm. Compared to the adenocarcinoma component, nuclei are larger and more pleomorphic. (B) The squamous component stained negatively for prostate specific antigen. All photos are taken with the same microscope at $400 \times$ magnification.

Prostate cancers with squamous differentiation frequently present with lower urinary tract symptoms, often without elevation of PSA. ${ }^{[9]}$ Wang $^{[2]}$ suggests that squamous carcinomas, in contrast to adenocarcinomas, occur more often around the prostatic urethra as opposed to the peripheral zone. Therefore, most squamous carcinomas present with obstructive symptoms that are thus initially treated with transurethral resection of the prostate, which is how many of them are initially diagnosed. While metastatic cancer is fatal, organ-confined disease can be cured by radical cystoprostatectomy. ${ }^{[1]}$ Wang $^{[2]}$ showed a 1-year survival of $78 \%$ in patients who underwent prostatectomy versus $38.7 \%$ in 
patients who did not undergo prostatectomy in review of 25 cases with patients who had adenosquamous carcinoma.
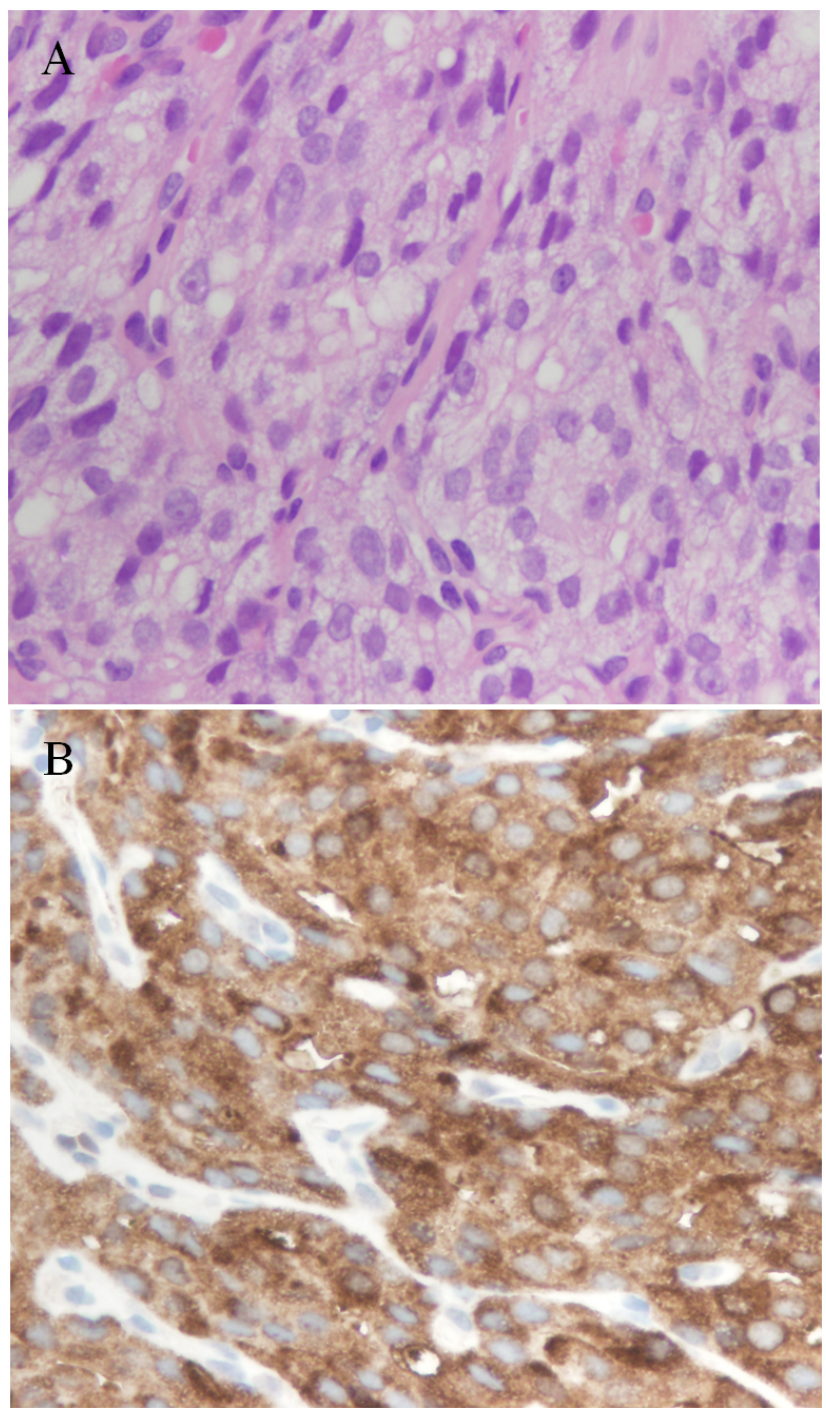

Figure 2. (A) In contrast to the squamous component, the conventional adenocarcinoma component, Gleason 4+4 ( score $=8$ ) shows smaller less pleomorphic nuclei and pale vacuolated cytoplasm. (B) The adenocarcinoma component stained positively for prostate specific antigen. All photos are taken with the same microscope at $400 \times$ magnification.

Serum prostate specific antigen, serum prostate acid phosphatase, and Gleason score are of limited value in these cases. ${ }^{[1,3,6]}$ Unlike adenocarcinomas, most squamous carcinomas show negative staining for prostate specific antigen, prostate-specific acid phosphatase, P501S, and prostatic acid phosphatase and positive staining for high molecular weight keratins, such as $34 \beta \mathrm{E} 12$ and AE3. ${ }^{[4-6,8,9]}$ Additionally, the squamous component can be differentiated by lack of staining with low molecular weight keratins, such as CAM 5.2 which will stain the glandular component. ${ }^{[6,9]}$ Squamous cell carcinomas in the prostate have additionally been noted to stain positive with racemase/AMACR, but this is not helpful in determining the origin because cancers of urothelial origin also stain with AMACR. ${ }^{[5]}$ Bassler $^{[8]}$ noted that in areas where adenocarcinoma and squamous components intermingled, the nuclei became larger and more pleomorphic like squamous carcinoma but maintained an immunohistochemical profile similar to adenocarcinoma. p53 mutation has been demonstrated in components with squamous differentiation, reflective of the tumor's aggressive behavior. ${ }^{[10]}$

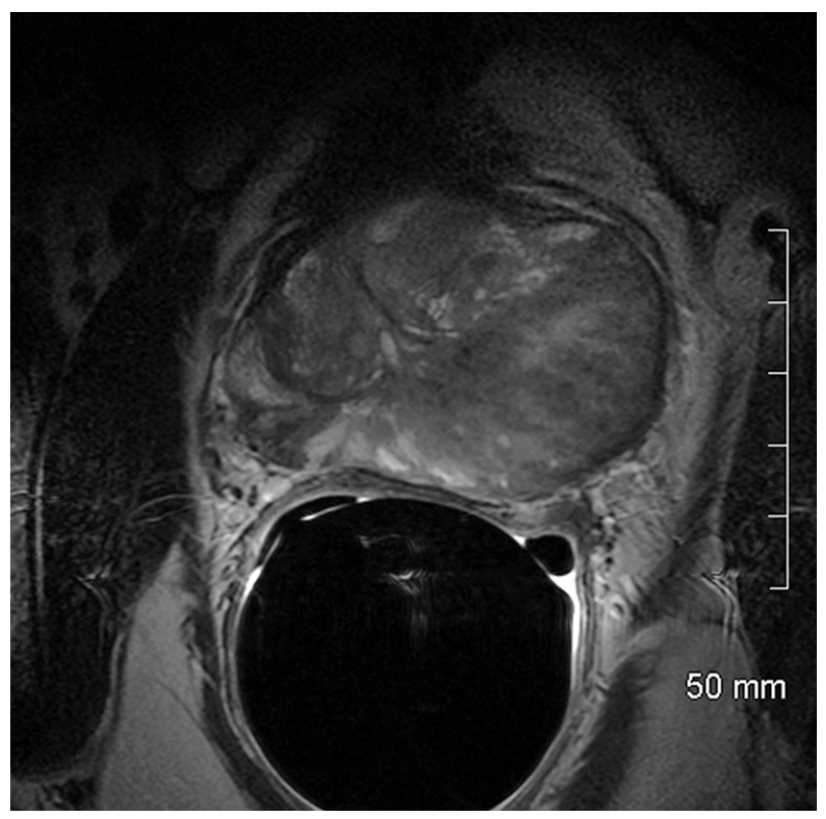

Figure 3. T2 weighted image with endorectal coil in place demonstrating a large left posterolateral hypointense mass causing significant bulge of the prostatic capsule and likely extracapsular spread

\section{Conclusion}

We report a case of a pure primary squamous cell carcinoma of the prostate which was particularly unique in that it presented simultaneously with a spatially separate small focus of high grade adenocarcinoma. Unlike the majority of previous reported cases, our case lacked a pre-existing history of hormonal or radiation therapy. Primary squamous cell carcinomas carry a poor prognosis compared with adenocarcinomas and thus should be a consideration in patients presenting with obstructive voiding symptoms without a significant rise in prostate specific antigen.

\section{CONFlicts OF InTEREST Disclosure}

The authors declare no conflict of interest. 


\section{REFERENCES}

[1] Al-Qassim Z, Mohammed A, Payne D, et al. Squamous cell carcinoma of the prostate following treatment with an LHRH-agonist: a rare case of transformation of adenocarcinoma of the prostate. Cent European J Urol. 2014; 67(1): 26-8. http://dx. doi .org/10.51 73/ceju.2014.01.art5

[2] Wang J, Wang FW, Lagrange CA, et al. Clinical features and outcomes of 25 patients with primary adenosquamous cell carcinoma of the prostate. Rare Tumors. 2010; 2(3): e47. http://dx.doi.org /10.4081/rt.2010.e47

[3] Munoz F, Franco P, Ciammella P, et al. Squamous cell carcinoma of the prostate: long-term survival after combined chemo-radiation. Radiat Oncol. 2007; 2: 15. PMid: 17407588. http://dx.doi.org $/ 10.1186 / 1748-717 \mathrm{X}-2-15$

[4] Parwani AV, Kronz JD, Genega EM, et al. Prostate carcinoma with squamous differentiation: an analysis of 33 cases. Am J Surg Pathol. 2004; 28(5): 651-7. PMid: 15105655. http://dx.doi.org/10. 1097/00000478-200405000-00014

[5] Arva NC, Das K. Diagnostic dilemmas of squamous differentiation in prostate carcinoma case report and review of the literature. Di- agn Pathol. 2011; 6: 46. http://dx.doi.org/10.1186/1746-1 596-6-46

[6] Helal M, Diaz JI, Tannenbaum A, et al. Postradiation therapy adenosquamous cell carcinoma of the prostate. Prostate Cancer Prostatic Dis. 2000; 3(1): 53-6. PMid: 12497163. http://dx.doi.o $\mathrm{rg} / 10.1038 / \mathrm{sj} \cdot \mathrm{pcan} .4500388$

[7] Al Adnani MS. Schistosomiasis, metaplasia and squamous cell carcinoma of the prostate: Histogenesis of the squamous cancer cells determined by localization of specific markers. Neoplasma. 1985; 32(5): 613-22. PMid: 2415839.

[8] Bassler TJ, Orozco R, Bassler IC, et al. Adenosquamous carcinoma of the prostate: Case report with DNA analysis, immunohistochemistry, and literature review. Urology. 1999; 53(4): 832-4. http://dx.doi.org/10.1016/S0090-4295(98)00418-X

[9] Mishra S, Goel H, Awasthi N, et al. Primary adenosquamous carcinoma of the prostate: a rare aggressive tumor. Clin Genitourin Cancer 2014; 12(1): 29-31. http://dx.doi.org/10.1016/j.clgc. 20 13.08 .006

[10] Zhang Z, Wang Y, Zhao Q, et al. Mixed adenocarcinoma, sarcomatoid carcinoma and adenosquamouscarcinoma of the prostate: A case report. Oncol Lett. 2014; 8(5): 2325-7. PMid: 25295118. 